Int. J. Electrochem. Sci., 15 (2020) 8070 - 8085

International Journal of

ELECTROCHEMICAL

SCIENCE

$\underline{\text { WWW.electrochemsci.org }}$

\title{
Electrochemical Behavior of Titanium in NaF Solutions and Characterization of Oxide Film Formed on its Surface
}

\author{
Awad Sadek Mogoda ${ }^{1, *}$ and K. M. Zohdy ${ }^{2}$ \\ ${ }^{1}$ Chemistry Department, Faculty of Science, Cairo University, Giza 12613, Egypt \\ ${ }^{2}$ Higher Technology Institute, Tenth of Ramadan City, Egypt \\ *E-mail: $\underline{\text { awad_mogoda@hotmail.com }}$
}

doi: $10.20964 / 2020.08 .16$

Received: 25 February 2020 / Accepted: 1 May 2020 / Published: 10 July 2020

Open-circuit potential, potentiodynamic polarization, cyclic voltammetry and electrochemical impedance spectroscopy (EIS) techniques have been used for studying the corrosion of titanium in sodium fluoride solutions of various concentrations $\left(10^{-3}\right.$ to $\left.1.5 \mathrm{M}\right)$. The potential results showed that the native film on titanium surface grows at a rate decreases as $\mathrm{F}^{-}$ion concentration increases. An activepassive transition peak was clearly observed in the voltammetric curves for fluoride concentrations ranging from $10^{-3}$ to $0.25 \mathrm{M}$ and did no longer appear for concentrations more than $0.25 \mathrm{M}$ due to such high concentrations help in formation of anodic oxide on titanium. The EIS and potentiodynamic polarization results gave more evidence for lowering the protectiveness of the primary passive layer on titanium with increasing fluoride concentration. Scanning electron microscopy (SEM) micrographs conformed the repairing of the cracks and defects present at the primary formed film on titanium surface after immersion in $0.01 \mathrm{M}$ sodium fluoride. Energy dispersive spectroscopy (EDS) spectra found out the presence of titanium oxide layer on the metal surface dipped in fluoride medium. The anodic film on titanium dissolves in fluoride solution because it has greater defective character than the native film which grows in the same solution.

Keywords. Titanium; open circuit potential; cyclic voltammetry; Impedance; SEM; EDS.

\section{FULL TEXT}

(C) 2020 The Authors. Published by ESG (www.electrochemsci.org). This article is an open access article distributed under the terms and conditions of the Creative Commons Attribution license (http://creativecommons.org/licenses/by/4.0/). 